\title{
Is aclidinium alone or combined with a $\angle A B A$ a rational choice for symptomatic COPD patients?
}

\author{
F. Blasi ${ }^{1 *} \mathbb{D}$, G. W. Canonica ${ }^{2}$ and M. Miravitlles ${ }^{3}$
}

\begin{abstract}
Background: As emphasized by international recommendations and largely confirmed by clinical experience, long-acting bronchodilators play a central role in the maintenance treatment of chronic obstructive pulmonary disease (COPD) due to their proven efficacy in reducing airflow obstruction and improving symptoms.

Main body: There are some important aspects to define with regard to inhalation therapy for COPD, particularly those concerning the selection criteria and the optimal use of long-acting bronchodilators. First of all, it needs to be determined in which patients and clinical situations monotherapy with one bronchodilator, such as a long-acting muscarinic antagonist (LAMA), should be considered adequate, and in which cases the use of combination therapies, such as the "double bronchodilation" with a LAMA and a long-acting $\beta 2$-agonist (LABA), should be preferred. Another critical issue concerns the effect of the frequency of daily administration of inhaled agents on the control of symptoms during the $24 \mathrm{~h}$. COPD symptoms are known to exhibit considerable circadian variability with worsening in the early morning, and a significant proportion of patients have disease-related sleep disorders which can adversely affect their quality of life. The worsening of symptoms in the early morning may be due, at least in part, to a reduction in airway caliber caused by an increased "cholinergic tone" at night. As such, the coverage of nighttime and early morning symptoms is a reasonable therapeutic goal, which can be achieved by many patients using LAMAs such as aclidinium bromide twice daily (BID). Therapeutic adherence is known to be a multifactorial phenomenon that is frequently affected by other aspects than dosing frequency, including the technical features and ease of use of the inhalers. To this end, it should be mentioned that certain new-generation inhalers such as Genuair ${ }^{\circledR}$ have been associated in clinical trials with higher patient preference.
\end{abstract}

Conclusion: In this work, in addition to presenting an overview of the main evidence on the efficacy of COPD treatment with the LAMA aclidinium bromide BID, we suggest some selection criteria for the monotherapy with one long-acting bronchodilator or the combination therapy with LAMA and LABA in COPD patients, with particular reference to specific clinical scenarios.

Keywords: COPD, Bronchodilators, Symptoms, Circadian variability, Therapeutic control, LAMA, Aclidinium, LAMA + LABA, Aclidinium + formoterol

\footnotetext{
* Correspondence: francesco.blasi@unimi.it

${ }^{1}$ Department of Pathophysiology and Transplantation, Università degli Studi

di Milano, Cardio-thoracic unit and Cystic Fibrosis Adult Center Fondazione

IRCCS Cà Granda Ospedale Maggiore Policlinico Milano, Milan, Italy

Full list of author information is available at the end of the article
}

\section{Ciomed Central}

(c) The Author(s). 2017 Open Access This article is distributed under the terms of the Creative Commons Attribution 4.0 International License (http://creativecommons.org/licenses/by/4.0/), which permits unrestricted use, distribution, and reproduction in any medium, provided you give appropriate credit to the original author(s) and the source, provide a link to the Creative Commons license, and indicate if changes were made. The Creative Commons Public Domain Dedication waiver (http://creativecommons.org/publicdomain/zero/1.0/) applies to the data made available in this article, unless otherwise stated. 


\section{Background}

Chronic obstructive pulmonary disease (COPD) is a common, preventable and treatable disease characterized by persistent, usually progressive airflow limitation, caused by both small airway disease (obstructive bronchiolitis) and parenchymal destruction (emphysema), the relative contributions of which vary from person to person. Characteristic symptoms of this chronic respiratory disease include dyspnea, cough and sputum production. Usually, a person suffering from COPD will decide to consult a physician because of the negative impact of their symptoms on their daily living activities, but also because of the persistence of symptoms or the occurrence of exacerbations.

COPD, a major cause of morbidity and mortality worldwide, involves a significant and increasing economic and social burden. The disability adjusted life years (DALYs) for a specific disease are calculated as the sum of the years of life lost due to premature mortality and the years of life lived with disability, adjusted for the severity of the disease. In 1990, COPD was the twelfth leading cause of lost DALYs worldwide, accounting for $2.1 \%$ of the total. It is predicted that by 2030 this disease will be the seventh leading cause of lost DALYs globally [1].

\section{Main text}

\section{Direct and indirect costs of COPD}

COPD involves a significant economic burden. In the European Union, the total direct costs of respiratory disease are estimated to be about $6 \%$ of the total health budget, with COPD alone accounting for 56\% (38.6 billion Euros) of this budget. In the United States, the costs of COPD are estimated to be $\$ 29.5$ billion for direct costs and $\$ 20.4$ billion for indirect costs. Exacerbations account for the greatest proportion of health care costs related to COPD. Therefore, the close correlation between disease severity and health care costs is not surprising, with the distribution of health expenditure changing with the progression of the disease. Any estimate of the direct medical costs of home care does not reflect the true home care costs for society, as it does not take into account the economic value of care provided by family members to COPD patients [2].

\section{Pathophysiology of COPD symptoms - circadian variability}

The traditional definition of COPD as a slowly progressive disease in which the deterioration of lung function is associated with an increase in symptoms, has been questioned by scientific evidence accumulated in recent years. Several studies have in fact demonstrated that the extent and perception of COPD symptoms are not as stable as previously believed, but show a variability that is not only seasonal, but also weekly and even daily, with symptoms often worsening at night and in the early morning $[3,4]$.

Circadian variability of COPD symptoms was also confirmed by a survey conducted on a sample of 803 COPD patients, which showed an increase in clinical manifestations especially in the early morning $(P<0.001$ versus "midday", "afternoon", "evening", "night" and "difficult to say" for all COPD patients; $P<0.001$ versus "midday" for patient with severe COPD symptoms) and at night [5]. There is also evidence that the main symptoms of COPD show different temporal trends during the $24 \mathrm{~h}$; in particular, it has been found that dyspnea, sputum production and cough tend to worsen especially in the morning, while wheezing shows a peak of variability at night, and tightness in the chest displays a highly variable trend during the $24 \mathrm{~h}$ [6].

From the pathophysiological viewpoint, the circadian variability of COPD symptoms, and especially the increase in symptoms at night/early morning, may be due, at least in part, to circadian modulation of the airway caliber by the cholinergic system. Like many other biological variables, airway caliber shows a certain variability during the $24 \mathrm{~h}$, reaching peak values around midday, with lower values at night and in the early morning. A central cholinergic mechanism is believed to be responsible for modulating the variability in airway caliber ("cholinergic tone"). The worsening of symptoms at night or in the early morning, which is found in many patients with COPD, may be at least partially attributed to a pathological increase in this circadian variation [7].

\section{Nighttime/early morning symptoms and decreased performance/QoL in COPD patients}

It is currently believed that improvements in "patientcentered" outcomes, including subjective symptoms, can reflect more accurately the effectiveness of pharmacological treatment of COPD compared with changes in forced expiratory volume in $1 \mathrm{~s}$ (FEV1), which are often transient and do not adequately reflect the real impact of treatment on the quality of life of patients.

A weak correlation between symptom perception by patients and FEV1 values is, in fact, often found in COPD; accordingly, subjective indicators relating to quality of life (QoL) and health-related quality of life (HR-QoL) are now considered as part of the therapeutic evaluation [8]. An example of such "patient-centered" outcomes is given by the circadian variability of COPD symptoms, which has been shown to adversely affect the performance of normal daily activities and to have a substantial negative impact on the quality of life [4].

Nighttime symptoms are particularly troublesome for patients with COPD as these symptoms are often associated with poor quality of sleep $[9,10]$. However, the presence of 
nocturnal symptoms in a patient with chronic airway disease should prompt health care professionals to make a differential diagnosis between COPD and asthma, as well as to exclude or confirm the presence of (concomitant) heart failure. To this end, a survey conducted by primary care physicians and respiratory specialists from several European countries (France, Germany, Italy, Spain and the UK) on a retrospective cohort of 2807 patients with COPD, showed that the majority of enrolled subjects (78\%) reported the presence of sleep disorders (i.e., difficulty in falling asleep, frequent nocturnal awakenings, difficulty in maintaining sleep), with nighttime symptoms associated with greater disease severity i.e., more daytime symptoms and more frequent exacerbations) $[11,12]$.

Similar to effects of nighttime symptoms, various studies have found that morning symptoms are also a significant burden to patients with COPD. Moreover, early morning has been reported as the worst time of a day by many COPD patients, especially among those with severe disease; moreover, early morning COPD symptoms limit patients' ability to perform their normal activities [13-15].

The recent observational ASSESS study, which included more than 700 patients with COPD, performed in a real-life context, has confirmed the significant prevalence of nighttime symptoms (52\%), which tend to be associated both with greater symptom severity, as assessed by the COPD Assessment Test (CAT), and higher prevalence of anxiety and depression, as assessed by the Hospital Anxiety and Depression Scale (HADS) [16]. In the clinical practice, however, the circadian variability is often not adequately taken into consideration in the therapeutic approach; for example, a real-life clinical study showed that drug treatment was not changed in more than half of patients surveyed, even though a significant worsening of symptoms over $24 \mathrm{~h}$ was noted. On the other hand, paying attention to the progression of symptoms over the course of $24 \mathrm{~h}$ is also important from the therapeutic point of view, as this can help to identify different types of patients, as well as to establish the most appropriate therapeutic strategy to mitigate the impact of symptoms on HR-QoL.

For these reasons, patients with COPD should be specifically questioned about daytime and nighttime symptoms and their impact on quality of life. The implementation of appropriate strategies for the optimal control of symptoms is also recommended, with particular regard to the time of maximum symptom intensity (e.g., nighttime, early morning) [4].

Inappropriate overuse of LABA + ICS and LABA + LAMA + ICS combinations in COPD patients that belong to $A$ or B-GOLD groups

Although the Global strategy for the diagnosis, management, and prevention of COPD (GOLD) recommendations indicate that monotherapy with a long-acting bronchodilators is the treatment of choice in group A and $\mathrm{B}$ patients, an inappropriate "overuse" of combinations with inhaled corticosteroids (ICS) and bronchodilators is often observed in the clinical practice. This inappropriate overuse of ICS-containing regimens is often in conflict with the need for a careful real-world assessment of the riskbenefit ratio of COPD treatments [17].

To this end, it is worth mentioning the results of a recent observational study conducted in the UK on a dataset of primary-care patients with COPD, which showed that the prescription pathways leading to a real-world use of "triple therapy" (TT) with LABA + LAMA + ICS differ considerably from those recommended by international recommendations [18]. In particular, this study found that ICS-containing TT regimens were also frequently prescribed to patients at low-risk of exacerbations and/or without concomitant asthma, who, according to current guidelines, do not need such treatments. The "progression" to TT occurred in $25 \%$ of cases within the first year of treatment and in $40 \%$ within the first two years [18] (Fig. 1).

The overuse of ICS-containing regimens can lead to several problems from the point of view of public health, with increased costs not justified by any superior efficacy, and from the viewpoint of safety, since chronic exposure to ICS can carry the risk of several side effects (including pneumonia, osteoporosis, etc) [2, 18]. Another fact emerging from the above UK survey is the low prescribing rates of long-acting bronchodilators as first-line therapy, which, together with the evidence of inappropriate prescribing of TT, emphasizes the need to provide better information and training for health care providers, in order to improve real-world implementation of COPD recommended management programs [18-22].

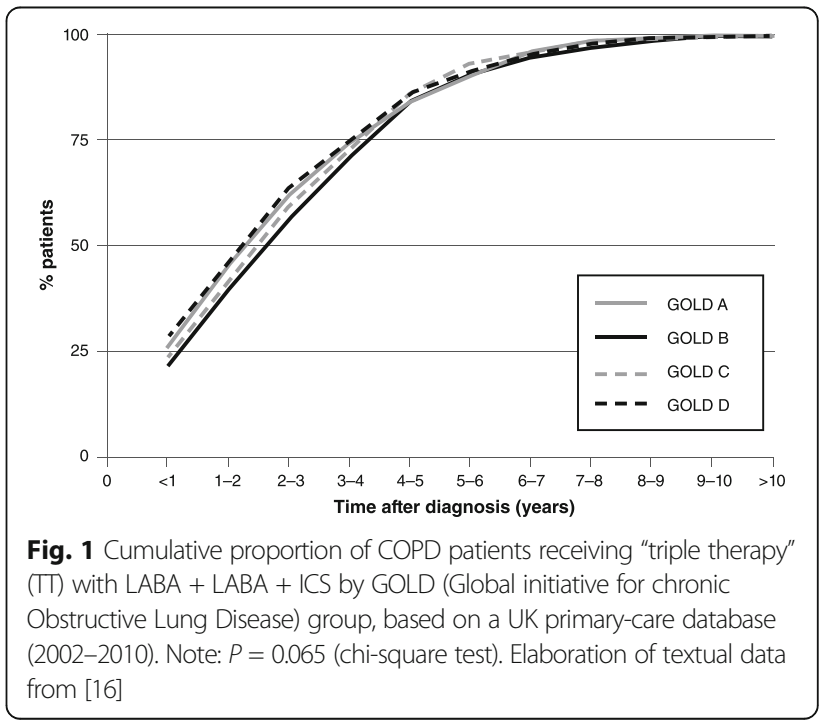


Rationale of bronchodilator monotherapy in symptomatic COPD patients

The administration of long-acting bronchodilators, such as LAMA or LABA, plays a central role in the control of symptomatic COPD [16]. There is also evidence showing that bronchodilators may have a significant role in the control of circadian variability of symptoms and in improving the quality of life of patients with COPD [4].

An interesting therapeutic "target" in this context is the increased "cholinergic tone" in patients with COPD; this phenomenon, due to various mechanisms not yet fully elucidated [23], seems to be particularly relevant at night and may contribute to the frequent occurrence of early morning symptoms in patients with COPD. The therapeutic role of LAMAs is therefore of great interest in view of these pathophysiological aspects, which are particularly important in patients with nocturnal symptoms and/or significant circadian variability of symptoms. The effectiveness of these drugs in reducing airway obstruction and lung hyperinflation, leading to an improvement in a variety of "patient-centered" outcomes, is well-documented [24]. In particular, due to their specific modulating action on cholinergic tone, LAMAs can effectively control the symptoms for $24 \mathrm{~h}$, especially when administered as a twice-daily regimen, which provides a better coverage of the "critical" nighttime period, as in the case of aclidinium bromide [25].

Role of the LAMA aclidinium bromide in COPD treatment Aclidinium bromide is a potent and selective LAMA, characterized by rapid onset and long duration of action; it also has a good cardiovascular safety profile, which may be attributed to its reduced residence time at M2 receptors and its rapid hydrolysis in plasma [26].

In experimental models, aclidinium showed a faster onset of action than the LAMA tiotropium [26]. Furthermore, in a study that assessed the onset of action of LAMAs (aclidinium, glycopyrronium and tiotropium, all administered at the approved clinical doses) in moderateto-severe COPD patients, bronchodilation induced by aclidinium and glycopyrronium was faster than that induced by tiotropium, without significant difference between aclidinium and glycopirronium [27].

Aclidinium bromide also exhibits potential antiinflammatory and anti-airway remodeling effects, as shown by studies of experimental animal models, which can be an "added value" in the therapeutic management of COPD [23].

For example, there is some evidence that aclidinium bromide could modulate the non-neuronal cholinergic system, a recently identified regulatory pathway in pulmonary inflammation and remodeling [28]. Dysfunction of the non-neuronal cholinergic system seems to be involved in the pathophysiology of COPD and to some extent in resistance to corticosteroid therapy; in fact, non-neuronal cholinergic system is over-expressed in corticosteroid-insensitive neutrophils from COPD patients, as evidenced by increases in the expression of muscarinic receptors (M2, M4 and M5), vesicular acetylcholine transporter (VAChT) and choline acetyltransferase (ChAT).

In a recent in vitro study, aclidinium bromide demonstrated anti-inflammatory effects on neutrophils from COPD patients, reversing their resistance to corticosteroids; in fact, the addition of aclidinium bromide increased the impaired anti-inflammatory properties of a corticosteroid (fluticasone propionate) by a mechanism involving the inhibition of Glucocorticoid Receptor Alpha (GR $\alpha)$ phosphorylation at Ser-226, the enhancement of corticosteroid- mediated Glucocorticoid Response Element (GRE) activation and the expression of corticosteroiddependent anti-inflammatory genes, i.e. Mitogen-activated Protein Kinase Phosphatase 1 (MKP1), Cysteine-RIch Secretory Protein LCCL Domain-containing 2 (CRISPLD2) and (GILZ) [28]. Among aclidinium bromide therapeutic properties, it seems to be interesting as well its favourable effect on hyperinflation and airflow limitation, that plays a very important pathophysiological role in inducing dyspnea and reducing quality of life (QoL) in COPD patients; in this regard, it has been recently demonstrated that aclidinium promotes a rapid and relevant desufflation and improves lung ventilation inhomogeneity, even in severe/very severe COPD patients [29].

The clinical efficacy of twice-daily (BID) aclidinium bromide is clearly demonstrated by the results of a large number of both placebo-controlled and active-comparator trials [30-36].

With regard to overall efficacy in the treatment of COPD, a Cochrane Review of 12 double-blind randomized controlled trials, lasting 4 to 52 weeks, on a total of 9547 patients with stable COPD, demonstrated that aclidinium bromide BID significantly improved quality of life by lowering the St. George's Respiratory Questionnaire (SGRQ) total score by 2.34 units compared to placebo (95\% confidence interval [CI] 3.18 to 1.51), significantly increased FEV1 with a mean difference of $0.09 \mathrm{~L}$ compared to placebo ( $95 \%$ CI 0.08 to 0.10 ), and reduced the number of patients with exacerbations requiring hospitalization (OR 0.64; 95\% CI 0.46 to 0.88) [31].

Aclidinium bromide BID can provide sustained bronchodilation over $24 \mathrm{~h}$, which is associated with significant improvement in FEV1 area under the curve (AUC), especially at night and early morning [32].

As regards the potential to effectively control the circadian variability of COPD symptoms, particularly interesting are the results of a multicenter, randomized, double-blind trial comparing aclidinium bromide $400 \mu \mathrm{g}$ BID with placebo and tiotropium $18 \mu \mathrm{g}$ OD in 795 patients with moderate-to-severe COPD, treated in a real-life 
context. During the period of treatment with aclidinium bromide $400 \mu \mathrm{g}$ BID, the proportions of patients with nighttime and morning symptoms and limitation in morning activities were significantly reduced from baseline ( $p<0.0001$ for all tests) [33].

The efficacy of aclidinium bromide in terms of symptom control over the entire 24-h period was also confirmed in a double-blind, randomized trial comparing aclidinium $400 \mu \mathrm{g}$ BID with tiotropium $18 \mu \mathrm{g}$ once-daily (OD) or placebo for six weeks on 414 patients with moderate-to-severe COPD [30]. At the end of the treatment period, symptom scores, assessed using specific questionnaires, were significantly reduced from baseline with both aclidinium $(p<0.0001)$ and tiotropium $(p<0.05)$ compared to placebo. It should be noted, however, that only aclidinium, but not tiotropium, resulted in significant improvements compared with placebo with regard to individual morning symptoms (phlegm, shortness of breath, wheezing, and cough) and severity of nocturnal symptoms; moreover, only aclidinium significantly reduced the limitation of activity caused by symptoms, with a significant difference compared to tiotropium $(p<0.05)$. The results of this study, in terms of greater potential of aclidinium to control the symptomatic manifestations of COPD, might be related to differences in dosing frequency between aclidinium and tiotropium; in particular, the second evening dose of aclidinium, administered in the evening, which is closer to the time of maximum intensity of respiratory symptoms, may be beneficial in improving nighttime and early morning symptoms.

In COPD patients, reducing the severity of respiratory symptoms is a very important treatment goal, as they are associated with poor health outcomes, reduced health status and increased exacerbation risk.

In this regard, a recent post-hoc analysis of pooled data from the aclidinium $400 \mu \mathrm{g}$ BID and placebo arms of two 24-week, double-blind, randomized studies, evaluating aclidinium monotherapy or combination therapy with aclidinium plus LABA formoterol, assessed the effect of aclidinium bromide on respiratory symptoms in moderateto-severe COPD patients. According to the conclusions of this paper, aclidinium $400 \mu \mathrm{g}$ BID significantly improved COPD respiratory symptoms, as assessed by the Evaluating Respiratory Symptoms in COPD (ERS-COPD) scale, irrespective of the patients' level of symptoms at baseline; in fact, net treatment benefit by aclidinium compared to placebo was found to be similar in patients with low or high levels of COPD symptoms [37].

Aclidinium bromide has confirmed its efficacy also in the long term, as demonstrated by the results of a 52 week double-blind, parallel group trial, performed on 605 patients with moderate-to-severe COPD. Treatment with aclidinium bromide BID resulted in clinically important improvements (reduction $\geq 4$ points from baseline) in symptom scores and in quality of life as assessed by SGRQ score at all study visits (performed at weeks 1, 12, 24, 36, 48 and 52) [34].

With regard to the tolerability profile, it should be noted that receptor selectivity and rapid plasma hydrolysis of aclidinium to inactive metabolites can explain the low incidence of systemic adverse events observed in clinical trials; such events, including anticholinergic side effects, were also generally mild $[35,36]$ (Table 1 ).

As a result of the large systemic and pre-systemic hydrolysis, the absolute bioavailability of aclidinium is very low $(<5 \%)$, and significantly lower than that of tiotropium and glycopyrronium ( $45 \%$ and $19 \%$, respectively) [38-40]. Cardiovascular adverse events have been reported with similar frequency in patients treated with aclidinium bromide and in those assigned to placebo group, supporting the safety of aclidinium in patients with COPD and concomitant cardiovascular disease $[41,42]$.

\section{Adherence to inhaled therapies: what is more important, frequency of administration or patient preference?}

Some authors have advanced the hypothesis that, in terms of patient's adherence to medical treatment, twice-daily dosing of inhaled medications is less favorable than once-daily dosing, but the available evidence

Table 1 Number (\%) of patients with potential anticholinergic adverse events by system organ class and preferred term (safety population) (Table 3 of [36], reproduced by permission)

System organ class/ Placebo Aclidinium $200 \mu \mathrm{g}$ Aclidinium $400 \mu \mathrm{g}$
preferred term $\quad(n=182) \quad(n=183) \quad(n=177)$

\begin{tabular}{llll}
\hline Cardiac disorders & & & \\
Tachycardia & 0 & 0 & $1(0.6)$ \\
Arrhythmia & $1(0.5)$ & 0 & 0 \\
Bradycardia & $2(1.1)$ & 0 & 0 \\
Palpitations & 0 & $2(1.1)$ & 0 \\
Increased heart rate ${ }^{\mathrm{a}}$ & 0 & $2(1.1)$ & 0 \\
Eye disorders & & & \\
Transient blindness & 0 & $1(0.5)$ & 0 \\
Reduced visual acuity & 0 & $1(0.5)$ & 0 \\
Gastrointestinal disorders & & 0 \\
Constipation & $3(1.6)$ & $1(0.5)$ & $3(1.7)$ \\
Dry mouth & $1(0.5)$ & $2(1.1)$ & $1(0.6)$ \\
Infections and infestation disorders & \\
Urinary tract infection & 0 & $3(1.6)$ & $1(0.6)$ \\
Nervous system disorders & & $1(0.6)$ \\
Optic neuritis & 0 & 0 & 0
\end{tabular}

Investigations is the system organ class for this preferred term 
in literature does not support this hypothesis. For instance, an observational study has demonstrated that the high frequency of drug administration may be a major problem for therapeutic adherence only in the case of three- and four-times-daily regimens, while there are no particularly significant differences between twice- and once-daily regimens [31].

On this subject there are interesting data from a recent study conducted in Spain on more than 16,000 patients treated with inhaled LAMAs (aclidinium, tiotropium, or glycopyrronium), which evaluated the degree of adherence to two different dosing regimens (once- or twice-daily).

This study showed that adherence to treatment with LAMAs was generally very high, irrespective of the molecule or inhalation device used; in particular, there was no evidence of lower adherence to LAMAs with BID dosing compared with OD dosing [43].

In this regard, an intriguing hypothesis, which needs to be verified in future studies, is that the better control of symptoms (especially of nighttime and early-morning symptoms) associated with BID dosing may be a significant factor for improving treatment adherence to this dosing regimen.

It should also be remembered that therapeutic adherence is a multifactorial process that can be affected by a number of factors different from dosing frequency, including: perceived efficacy of treatment, side effects, number of concomitant medications, as well as patient's satisfaction with, or preference for, the inhaler device [31].

With regard to the latter, it should be emphasized that, in order to achieve adequate adherence and, thus, the maximum benefit from treatment, it is important that the inhalation device is used correctly. Since an inadequate inhaler technique may compromise treatment efficacy, it is desirable to have devices that are easy to use, with a few simple "steps" for dosing, and with feedback mechanisms to confirm successful inhalation of the dose. An example of this kind of device is Genuair ${ }^{\circ}$, a multidose, breath-actuated dry powder inhaler (DPI), designed to deliver aclidinium bromide. Genuair incorporates a number of technological features that enhance its performance and safety of use, including the patented "cyclone" technology to improve deaggregation of aerosol particles, thus achieving high drug deposition in the lungs, as well as visual and acoustic feedback mechanisms that make the device simple and easy-to-use for the patient [44].

Ease of use, efficiency, and low probability of critical errors with Genuair are clinically reflected in an increased patient preference for this inhaler compared to other frequently used devices. To this end, in a recent Italian study investigating the "usability" of this device in a representative sample of the elderly population (256 individuals with COPD, and 89 with hand arthritis/arthrosis), Genuair ${ }^{\circ}$ was considered a well-accepted, easy-to-use device by the great majority of patients studied; moreover, the mean time to learn and perform the inhalation correctly was only 1'38', and more than $70 \%$ of patients took less than 2 min to perform this task [45] (Fig. 2).

\section{Aclidinium/formoterol: rationale of combination for clinical use in COPD patients}

The long-acting bronchodilators, LAMA and LABA, play an important role in the treatment of COPD, as emphasized by international recommendations $[2,46,47]$. The combined use of bronchodilators belonging to different drug classes, acting on different receptor systems, can improve lung function and symptoms, which is particularly beneficial in patients with moderate-to-severe COPD [41].

The rationale of the "double bronchodilation" with LAMA and LABA lies in the fact that the relaxation of airway smooth muscle (and the resulting bronchodilation) can be achieved by two main mechanisms:

- inhibition of acetylcholine signaling, mediated by muscarinic $\mathrm{M} 3$ receptors, on airway smooth muscle with LAMA;

- stimulation of $\beta 2$-adrenergic receptors with LABA.

The simultaneous pharmacological targeting of these two mechanisms of bronchodilation can maximize the bronchodilator response, without the need to increase the dose of each component of the combination and thereby reduces the risk of adverse events [48-50].

Fixed-dose combinations (FDCs) of LAMA and LABA offer the potential of good convenience and compliance. Among the different LAMA/LABA FDCs, the combinations involving twice-daily dosing, such as the LAMA aclidinium + LABA formoterol, may be able to better tailor drug therapy to the individual needs of patients, including the control of early-morning symptoms, which are particularly intense and/or frequent in patients with moderate-to-severe COPD [51].

This was confirmed by a pooled analysis of two 24week, double-blind, placebo-controlled, randomized phase III trials evaluating the efficacy of the FDC aclidinium/ formoterol on 3394 patients with moderate-to-severe COPD. This analysis showed that the FDC aclidinium/ formoterol was able to improve early morning symptoms and to reduce the limitation of early-morning activities significantly more $(p<0.05)$ than placebo and monotherapy with LAMA or LABA [42].

\section{The correct use of bronchodilators in COPD, "when, and to whom": therapeutic suggestions}

The current availability of a number of active agents and a variety of drug classes for the treatment of COPD 
A

Overall, do you think that the inhaler is easy to use?
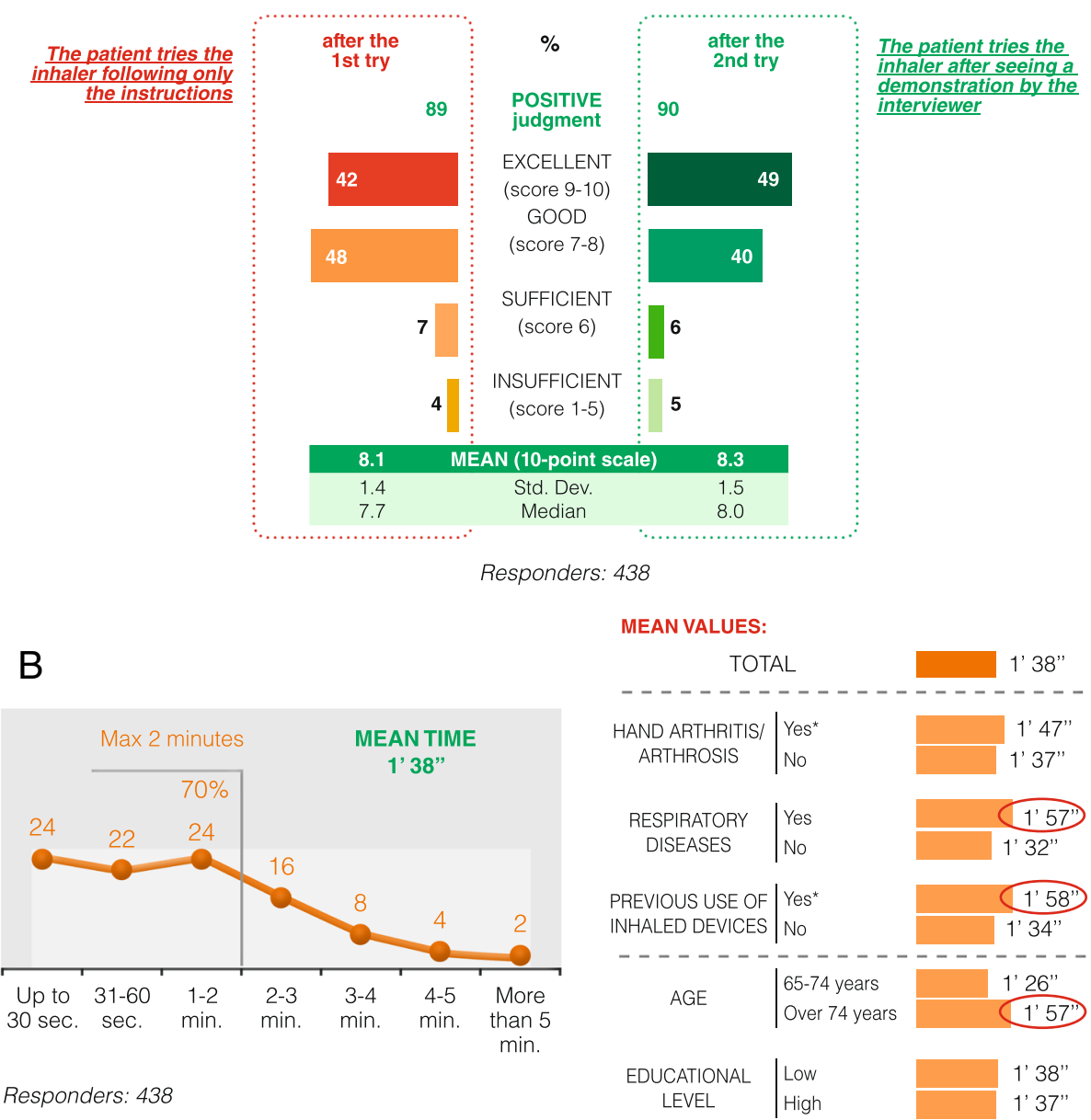

Fig. 2 Assessment of ease of use of the device (Panel a) and mean time to learn the inhaler technique and to perform a correct inhalation (Panel $\mathbf{b}$ ), as reported by a recent Italian study which evaluated the usability of the Genuair device in a representative sample of the elderly population with COPD/hand arthritis/arthrosis. Elaboration of textual data from [45]

makes it often difficult for the physician to select the optimal treatment. In our view, the selection of the most appropriate treatment should take into consideration the extent of the "disease impact" in a given patient, including the severity of spirometric obstruction, the symptom burden, the frequency of exacerbations and disease control [48]. Although LAMA monotherapy may be adequate to control the disease in certain groups of patients with COPD, combined therapy with LAMA and LABA, in combination with an ICS if needed, is often necessary for specific clinical situations or certain levels of disease severity.

What is nowadays the therapeutic role in COPD patients of LAMA used in monotherapy and/or in combination with other classes of inhaled drugs, such as LABA or ICS? We advance some therapeutic suggestions, taking also into account results of the recent FLAME trial and the posthoc analysis of the WISDOM trial [51, 52] [(Fig. 3)]:
- COPD patients with $\leq 1$ exacerbation/year and baseline FEV1 $\geq 50 \%$ predicted, first-line treatment with LAMA or LABA; baseline FEV1 < 50\% and/or severe symptoms of dyspnea, first line treatment LAMA/LABA.

- COPD patients with $\geq 2$ exacerbation/year and low eosinophils blood count $[<300 / \mu l]$, first-line treatment with LAMA/LABA; high blood eosinophil count $[\geq 300 / \mu \mathrm{l}]$, first line treatment with LABA/ICS or LAMA/LABA/ICS; despite a high eosinophil count, LAMA/LABA can be considered first line treatment in absence of allergic or asthma history.

In case of lack of control a step-up therapy should be considered.

In any case it should be taken into account that the literature evidence suggests that in patients with mild 


\section{Maintenance treatment of COPD}

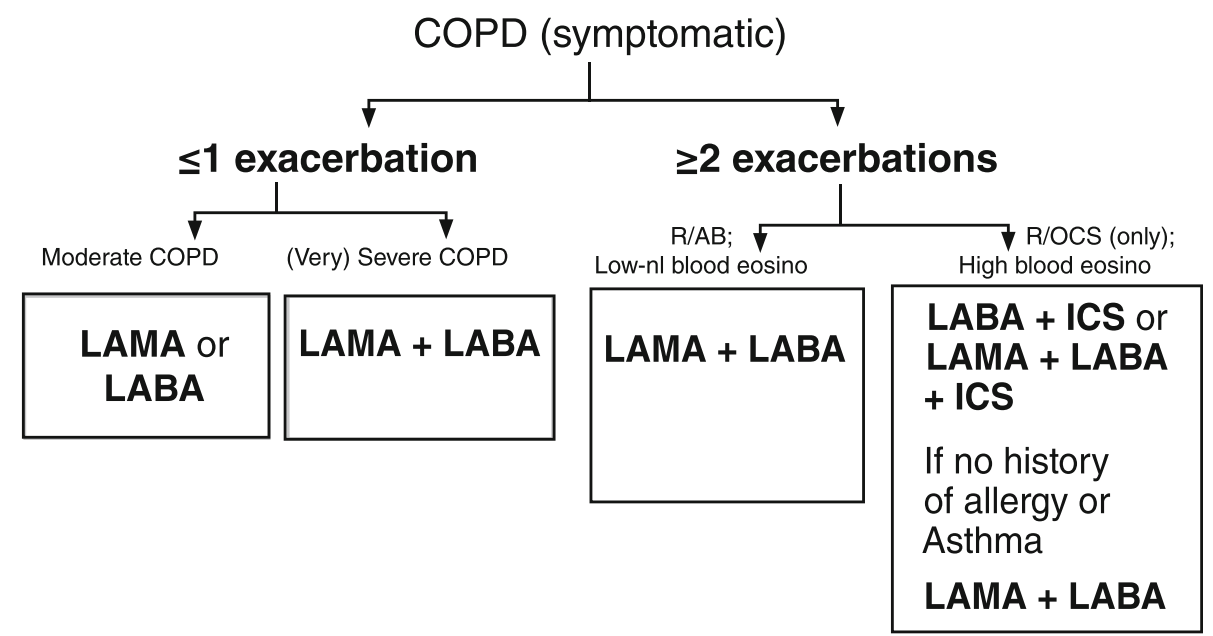

Fig. 3 Therapeutic suggestions in COPD, taking also into account results of recent FLAME trial and the post-hoc analysis of the WISDOM trial. Elaboration of textual data from [51, 52]

airflow obstruction according to the GOLD spirometric classification and relatively moderate symptoms, LAMA monotherapy (for example, with aclidinium bromide; other LAMA commercially available are glycopyrronium bromide, tiotropium and umeclidinium) is often sufficient to provide adequate symptom control. In the same type of patients, but with more significant symptoms, the use of "double bronchodilation" with LAMA/LABA FDC (such as aclidinium + formoterol; other LAMA/LABA FDC commercially available are indacaterol/glycopyrronium, olodaterol/tiotropium, vilanterol/umeclidinium) can be considered. This LAMA/LABA is also preferred in patients with moderate-to-severe "disease impact", including patients with moderate-to-severe airflow limitation and significant symptoms; patients with moderate-to-severe disease, who remain symptomatic despite monotherapy; patients with moderate-to-severe symptoms, but without frequent exacerbations. The use of a LAMA can be also considered as add-on therapy to LABA or ICS/LABA in case of very severe "disease impact", e.g., in patients with severe spirometric obstruction suffering from frequent exacerbations. In these patients, with high eosinophil count but without history of allergy and asthma, a LAMA/LABA combination can be proposed as first choice.

\section{Conclusion}

Bronchodilator therapy with LAMA, as monotherapy or in combination with LABA, is one cornerstone of COPD treatment. Given the circadian variability of symptoms in patients with COPD, due at least in part to the typical increased "cholinergic tone" in these subjects, the coverage of nighttime and early-morning symptoms should be considered a reasonable therapeutic target, which can be achieved by using an appropriate treatment (e.g. a LAMA such as aclidinium bromide, administered twice daily). Therapeutic adherence is often good in patients treated with twice-daily LAMAs, especially if they use a simple and easy-to-use inhalation device. The selection of LAMA monotherapy, combination therapy with LAMA + LABA, or add-on therapy with LAMA to LABA/ICS, should be individualized based on a comprehensive evaluation of the patient with COPD, taking into account the degree of airway obstruction, the symptom burden, eosinophil count, history of allergy and asthma and the frequency and type of exacerbations.

\section{Abbreviations}

BID: Bis in die (i.e. twice daily); CAT: COPD assessment test; ChAT: Choline acetyltransferase; Cl: Confidence interval; COPD: Chronic obstructive pulmonary disease; CRISPLD2: Cysteine-rich secretory protein LCCL domain-containing 2; DALY: Disability adjusted life years; ERS-COPD: Evaluating Respiratory Symptoms in COPD; FDC: Fixed dose combination; GILZ: Glucocorticoid-induced leucine zipper; GOLD: Global strategy for the diagnosis, management, and prevention of COPD; GRE: Glucocorticoid response element; GRa: Glucocorticoid receptor alpha; HADS: Hospital Anxiety and Depression Scale; HR-QoL: Health-related quality of life; ICS: Inhaled CorticoSteroid; LABA: Long-acting $\beta 2$-agonist; LAMA: Long-acting muscarinic antagonist; MKP-1: Mitogen-activated protein kinase phosphatase 1; OCS: Oral CortiCosteroid; OD: Once daily; QoL: Quality of life; SGRQ: St. George's Respiratory Questionnaire; TT: Triple therapy; VAChT: Vesicular acetylcholine transporter

\section{Acknowledgements}

Many thanks to Guy Brusselle for his suggestions and for granting the use of the Fig. 3.

\section{Funding}

This work was funded by Momento Medico srl, which has contributed to the costs for the literature selection and editorial assistance. The work has been partially supported by an unrestricted grant by Laboratori Guidotti SpA. 


\section{Availability of data and materials}

Not applicable.

\section{Authors' contributions}

FB has coordinated the works of the scientific board and drafted the text. MM and GWC contributed actively and effectively in the definition of the contents and in the revision of the manuscript. All authors read and approved the final manuscript.

\section{Competing interests}

Francesco Blasi has received research grants from Chiesi, Zambon, and Pfizer, congress lecture fees from Guidotti, Menarini, GSK, Chiesi, Pfizer, and Novartis, and consultancy fees from AstraZeneca, Menarini, Mundipharma,Novartis, GSK, Teva and Pfizer.

Giorgio Walter Canonica, has received research grants as well as lecture or advisory board fees from Menarini, Alk-Abello', Allergy Therapeutics, Anallergo, AstraZeneca, Boehringer Ingelheim, Chiesi Farmaceutici, Circassia, Danone, Faes, Genentech, Guidotti-Malesci, Glaxo Smith Kline, Hal Allergy, Lofarma, Meda, Merck, Mundipharma, Novartis, Phadia, Recordati-InnovaPharma, Roche, Sanofi-Aventis, Schering Plough, Stallergene, UCB Pharma, Uriach Pharma, Teva, Thermo Fisher, Valeas.

Marc Miravitlles has received speaker fees from Almirall, Boehringer Ingelheim, AstraZeneca, Chiesi, GlaxoSmithKline, Menarini, Teva, Grifols and Novartis, and consulting fees from Almirall, Bayer Schering, Boehringer Ingelheim, GlaxoSmithKline, Gebro Pharma, CLS Behring, Cipla, Medilmmune, Teva, Takeda, Novartis and Grifols.

\section{Consent for publication}

Not applicable.

\section{Ethics approval and consent to participate}

Not applicable.

\section{Author details}

'Department of Pathophysiology and Transplantation, Università degli Studi di Milano, Cardio-thoracic unit and Cystic Fibrosis Adult Center Fondazione IRCCS Cà Granda Ospedale Maggiore Policlinico Milano, Milan, Italy. ${ }^{2}$ Department of Biomedical Science, Personalized Medicine Clinic: Asthma \& Allergy - Humanitas Clinical and Research Center, Humanitas University Rozzano (Milano), Milan, Italy. ${ }^{3}$ Pneumology Department, Hospital Universitari Vall d'Hebron, Barcelona, Spain.

Received: 6 November 2016 Accepted: 13 January 2017

Published online: 18 January 2017

\section{References}

1. Lozano R, Naghavi M, Foreman K, Lim S, Shibuya K, et al. Global and regional mortality from 235 causes of death for 20 age groups in 1990 and 2010: a systematic analysis for the Global Burden of Disease Study 2010. Lancet. 2012;380(9859):2095-128. doi:10.1016/S0140-6736(12)61728-0.

2. GOLD. Global strategy for the diagnosis, management, and prevention of COPD. Update 2016. http://goldcopd.org/global-strategy-diagnosismanagement-prevention-copd-2016/. Accessed 16 Jan 2017.

3. Kessler R, Partridge MR, Miravitlles M, Cazzola M, Vogelmeier C, Leynaud D, Ostinelli J. Symptom variability in patients with severe COPD: a panEuropean cross-sectional study. Eur Respir J. 2011;37(2):264-72. doi:10.1183/09031936.00051110.

4. Lopez-Campos JL, Calero C, Quintana-Gallego E. Symptom variability in COPD: a narrative review. Int J COPD. 2013:8:231-8. doi:10.2147/COPD.S42866.

5. Partridge MR, Karlsson N, Small IR. Patient insight into the impact of chronic obstructive pulmonary disease in the morning: an internet survey. Curr Med Res Opin. 2009;25:2043-8. doi:10.1185/03007990903103006.

6. Kuyucu T, Güçlü SZ, Şaylan B, Demir C, Şenol T, Güner S, et al. A cross-sectional observational study to investigate daily symptom variability, effects of symptom on morning activities and therapeutic expectations of patients and physicians in COPD-SUNRISE study. Tüberküloz ve Toraks Dergisi. 2011;59(4):328-39.

7. Calverley MA, Lee A, Towse L, van Noord J, Witek TJ, Kelsen S. Effect of tiotropium bromide on circadian variation in airflow limitation in chronic obstructive pulmonary disease. Thorax. 2003;58:855-60.
8. Feldman GJ. Improving the quality of life in patients with chronic obstructive pulmonary disease: focus on indacaterol. Int J COPD. 2013:8:89-96. doi:10.2147/COPD.S31209.

9. Scharf SM, Maimon N, Simon-Tuval T, Bernhard-Scharf BJ, Reuveni H, Tarasiuk A Sleep quality predicts quality of life in chronic obstructive pulmonary disease. Int J Chron Obstruct Pulmon Dis. 2010;6:1-12. doi:10.2147/COPD.S15666.

10. Omachi TA, Blanc PD, Claman DM, Chen H, Yelin EH, Julian L, Katz PP. Disturbed sleep among COPD patients is longitudinally associated with mortality and adverse COPD outcomes. Sleep Med. 2012;13(5):476-83. doi:10.1016/j.sleep.2011.12.007.

11. Price D, Small M, Milligan G, Higgins V, Garcia Gil E, Estruch J. Impact of night-time symptoms in COPD: a real-world study in five European countries. Int J COPD. 2013;8:595-603. doi:10.2147/COPD.S48570.

12. Small M, Higgins $V$, Lees $A$, Johns $N$, Mastrangelo A, Nazareth $T$, Turner SJ. Physician-Patient Concordance in Pharmacological Management of Patients with COPD. COPD. 2015;12(5):473-83.

13. Stephenson JJ, Cai Q, Mocarski M, Tan H, Doshi JA, Sullivan SD. Impact and factors associated with nighttime and early morning symptoms among patients with chronic obstructive pulmonary disease. Int J Chron Obstruct Pulmon Dis. 2015;10:577-86. doi:10.2147/COPD.S76157.

14. Roche N, Chavannes NH, Miravitlles M. COPD symptoms in the morning: impact, evaluation and management. Respir Res. 2013;14:112. doi:10.1186/1465-9921-14-112.

15. Roche N, Small M, Broomfield S, Higgins V, Pollard R. Real world COPD: association of morning symptoms with clinical and patient reported outcomes. COPD. 2013;10(6):679-86. doi:10.3109/15412555.2013.844784.

16. Miravitlles M, Wort H, Cataluña JJS, Price D, et al. Observational study to characterise 24-h COPD symptoms and their relationship with patientreported outcomes: results from the ASSESS study. Respir Res. 2014;15:122. doi:10.1186/s12931-014-0122-1.

17. Lahousse L, Verhamme KM, Stricker BH, Brusselle GG. Cardiac effects of current treatments of chronic obstructive pulmonary disease. Lancet Respir Med. 2016;4(2):149-64. doi:10.1016/S2213-2600(15)00518-4.

18. Brusselle G, Price D, Gruffydd-Jones K, Miravitlles M, Keininger DL, Stewart R, Baldwin M, Jones RC. The inevitable drift to triple therapy in COPD: an analysis of prescribing pathways in the UK. Int J Chron Obstruct Pulmon Dis. 2015;10:2207-17. doi:10.2147/COPD.S91694.

19. Wurst KE, Punekar YS, Shukla A. Treatment evolution after COPD diagnosis in the UK primary care setting. PLoS One. 2014;9(9), e105296. doi:10.1371/journal.pone.0105296.

20. Miyazaki M, Nakamura H, Takahashi S, Chubachi S, Sasaki M, Haraguchi M, Terai H, Ishii M, Fukunaga K, Tasaka S, Soejima K, Asano K, Betsuyaku T, Keio COPD Comorbidity Research (K-CCR) group. The reasons for triple therapy in stable COPD patients in Japanese clinical practice. Int J Chron Obstruct Pulmon Dis. 2015;10:1053-9. doi:10.2147/COPD.S79864.

21. Barrecheguren M, Monteagudo M, Ferrer J, Borrell E, Llor C, Esquinas C, Miravitlles M. Treatment patterns in COPD patients newly diagnosed in primary care. A population-based study. Respir Med. 2016;111:47-53. doi:10.1016/j.rmed.2015.12.004.

22. Wei YF, Kuo PH, Tsai YH, Tao CW, Cheng SL, Lee CH, Wu YK, Chen NH, Hsu WH, Hsu JY, Lin MS, Wang CC. Factors associated with the prescription of inhaled corticosteroids in GOLD group A and B patients with COPD - subgroup analysis of the Taiwan obstructive lung disease cohort. Int J Chron Obstruct Pulmon Dis. 2015;10:1951-6. doi:10.2147/COPD.S88114.

23. Joos GF. Aclidinium bromide for the treatment of chronic obstructive pulmonary disease. Drugs Today. 2012;48(12):757-63. doi:10.1358/dot.2012.48.12.1885871.

24. Tashkin DP, Ferguson GT. Combination bronchodilator therapy in the management of chronic obstructive pulmonary disease. Respir Res. 2013;14:49. doi:10.1186/1465-9921-14-49.

25. Fuhr R, Magnussen H, Sarem K, Llovera AR, Kirsten AM, Falques M, Caracta CF, Garcia GE. Efficacy of aclidinium bromide $400 \mu \mathrm{g}$ twice daily compared with placebo and tiotropium in patients with moderate to severe COPD. Chest. 2012;141:745-52. doi:10.1378/chest.11-0406.

26. Gavaldà A, Miralpeix M, Ramos I, Otal R, Carreño C, et al. Characterization of aclidinium bromide, a novel inhaled muscarinic antagonist, with long duration of action and a favorable pharmacological profile. J Pharmacol Exp Ther. 2009;331:740-51. doi:10.1124/jpet.109.151639.

27. Rogliani P, Calzetta L, Ora J, Lipsi R, Segreti A, Matera MG, Cazzola M. Pharmacological assessment of the onset of action of aclidinium and glycopyrronium versus tiotropium in COPD patients and human isolated bronchi. Eur J Pharmacol. 2015;761:383-90. doi:10.1016/j.ejphar.2015.04.042. 
28. Milara J, Cervera A, de Diego A, Sanz C, Juan G, Gavaldà A, Miralpeix M, Morcillo E, Cortijo J. Non-neuronal cholinergic system contributes to corticosteroid resistance in chronic obstructive pulmonary disease patients. Respir Res. 2016;17(1):145.

29. Contoli M, Solidoro P, Di Marco F, Scichilone N, Corsico A, Braido F, Santus P. Effects of aclidinium on determinants of COPD severity symptoms and quality of life. Int J COPD. 2016;11:3043-50. https://doi.org/10.2147/COPD.S122433.

30. Kerwin EM, D'Urzo AD, Gelb AF, Lakkis H, Garcia Gil E, Caracta CF, ACCORD I study investigators. Efficacy and safety of a 12-week treatment with twicedaily aclidinium bromide in COPD patients (ACCORD COPD I). COPD. 2012 9:90-101. doi:10.3109/15412555.2012.661492.

31. Ni H, Soe Z, Moe S. Aclidinium bromide for stable chronic obstructive pulmonary disease (Review). Cochrane Database Syst Rev. 2014;9, CD010509. doi:10.1002/14651858.CD010509.pub2.

32. Beier J, Kirsten A-M, Mróz R, Segarra R, Chuecos F, Caracta C, Garcia GE. Efficacy and Safety of Aclidinium Bromide Compared with Placebo and Tiotropium in Patients with Moderate-to-Severe Chronic Obstructive Pulmonary Disease: Results from a 6-week, Randomized, Controlled Phase Illb Study. COPD. 2013;00:1-12. doi:10.3109/15412555.2013.814626.

33. Marth K, Schuller E, Pohl W. Improvements in patient-reported outcomes: a prospective, non-interventional study with aclidinium bromide for treatment of COPD. Respir Med. 2015;109(5):616-24. doi:10.1016/j.rmed.2015.02.004

34. Gelb AF, Tashkin DP, Make BJ, Zhong X, Garcia Gil E, Caracta C, LAS-MD-35 study investigators. Long-term safety and efficacy of twice-daily aclidinium bromide in patients with COPD. Respir Med. 2013;107(12):1957-65. doi:10. 1016/j.rmed.2013.07.001.

35. Woods JA, Nealy KL, Barrons RW. Aclidinium bromide: an alternative longacting inhaled anticholinergic in the management of chronic obstructive pulmonary disease. Ann Pharmacother. 2013;47(7-8):1017-28. doi:10.1345/aph.1S002.

36. Rennard SI, Scanlon PD, Ferguson GT, et al. ACCORD COPD II: A randomized clinical trial to evaluate the 12-week efficacy and safety of twice-daily aclidinium bromide in chronic obstructive pulmonary disease patients. Clin Drug Investig. 2013;33(12):893-904. doi:10.1007/s40261-013-0138-1.

37. Jones PW, Leidy NK, Hareendran A, Lamarca R, Chuecos F, Garcia GE. The effect of aclidinium bromide on daily respiratory symptoms of COPD, measured using the Evaluating Respiratory Symptoms in COPD (E-RS: COPD) diary: pooled analysis of two 6-month Phase III studies. Respir Res. 2016;17(1): 61. doi:10.1186/s12931-016-0372-1.

38. Aclidinium bromide, Summary of Product Characteristics. https://farmaci. agenziafarmaco.gov.it. Accessed 16 Jan 2017.

39. Glycopyrronium, Summary of Product Characteristics.https://farmaci. agenziafarmaco.gov.it. Accessed 16 Jan 2017.

40. Tiotropium, Summary of Product Characteristics. https://farmaci. agenziafarmaco.gov.it. Accessed 16 Jan 2017.

41. Cazzola M, Page CP, Matera MG. Aclidinium bromide for the treatment of chronic obstructive pulmonary disease. Expert Opin Pharmacother. 2013; 14(9):1205-14. doi:10.1517/14656566.2013.789021.

42. Bateman ED, Chapman KR, Singh D, D'Urzo AD, Molins E, Leselbaum A, Gil EG. Aclidinium bromide and formoterol fumarate as a fixed-dose combination in COPD: pooled analysis of symptoms and exacerbations from two six-month, multicentre, randomised studies (ACLIFORM and AUGMENT). Respir Res. 2015:16:92. doi:10.1186/s12931-015-0250-2.

43. Izquierdo JL, Paredero JM, Piedra R. Relevance of dosage in adherence to treatment with long-acting anticholinergics in patients with COPD. Int J Chron Obstruct Pulmon Dis. 2016;11:289-93. doi:10.2147/COPD.S96948.

44. Chrystyn $\mathrm{H}$, Niederlaender C. The Genuair inhaler: a novel, multidose dry powder inhaler. Int J Clin Pract. 2012;66:309-17. doi:10.1111/j.1742-1241.2011.02832x.

45. Blasi F, Canonica GW, Centanni S, Mereu C, Bernabei R, Paolisso G, Incalzi RA, Corsico A, Di Marco F, Milanese M, Pagano F, Santus P, Scichilone N, Sumberesi M, Braido F, Baiardini I. Genuair ${ }^{\oplus}$ Usability Test: Results of a National Public Survey of the Elderly. COPD. 2016;13(3):367-71. doi:10.3109/15412555.2015.1067675.

46. Bettoncelli G, Blasi F, Brusasco V, Centanni S, Corrado A, De Benedetto F, De Michele F, Di Maria GU, Donner CF, Falcone F, Mereu C, Nardini S, Pasqua F, Polverino M, Rossi A, Sanguinetti CM. The clinical and integrated management of COPD An official document of AIMAR (Interdisciplinary Association for research in Lung Disease), AIPO (Italian Association of Hospital Pulmonologists), SIMER (Italian Society of Respiratory Medicine), SIMG (Italian Society of General Medicine). Multidiscip Respir Med. 2014;9(1): 25. doi:10.1186/2049-6958-9-25.
47. Miravitlles M, Vogelmeier C, Roche N, Halpin D, Cardoso J, Chuchalin AG, Kankaanranta H, Sandström T, Śliwiński P, Zatloukal J, Blasi F. A review of national guidelines for management of COPD in Europe. Eur Respir J. 2016; 47(2):625-37. doi:10.1183/13993003.01170-2015.

48. Soler-Cataluña JJ, Alcázar-Navarrete B, Miravitlles M. The concept of control of COPD in clinical practice. Int J Chron Obstruct Pulmon Dis. 2014;9:1397-405. doi:10.2147/COPD.S71370.

49. Meurs H, Oenema TA, Kistemaker LEM, Gosens R. A new perspective on muscarinic receptor antagonism in obstructive airways diseases. Curr Opin Pharmacol. 2013;13(3):316-23. doi:10.1016/j.coph.2013.04.004.

50. Tashkin DP. The safety of anticholinergic bronchodilators for the treatment of chronic obstructive pulmonary disease. Expert Opin Drug Saf. 2015; 14(11):1759-72. doi:10.1517/14740338.2015.1093621.

51. Watz H, Tetzlaff $K$, Wouters EF, Kirsten A, Magnussen $H$, Rodriguez-Roisin R, Vogelmeier C, Fabbri LM, Chanez P, Dahl R, Disse B, Finnigan H, Calverley PM. Blood eosinophil count and exacerbations in severe chronic obstructive pulmonary disease after withdrawal of inhaled corticosteroids: a post-hoc analysis of the WISDOM trial. Lancet Resp Med. 2016;4:390-8. doi:10.1016/S2213-2600(16)00100-4

52. Wedzicha JA, Banerji D, Chapman KR, Vestbo J, Roche N, Ayers RT, Thach C, Fogel R, Patalano F, Vogelmeier CF, FLAME Investigators. IndacaterolGlycopyrronium versus Salmeterol-Fluticasone for COPD. N Engl J Med. 2016;374(23):2222-34. doi:10.1056/NEJMoa1516385.

\section{Submit your next manuscript to BioMed Central and we will help you at every step:}

- We accept pre-submission inquiries

- Our selector tool helps you to find the most relevant journal

- We provide round the clock customer support

- Convenient online submission

- Thorough peer review

- Inclusion in PubMed and all major indexing services

- Maximum visibility for your research

Submit your manuscript at www.biomedcentral.com/submit
C Biomed Central 